\title{
Research Article \\ Effects of Groove Feature on Shear Behavior of Steel-Sand Interface
}

\author{
Jukun Guo, ${ }^{1,2}$ Xiaowei Wang, ${ }^{2}$ Shengyou Lei, ${ }^{1}$ Rui Wang, ${ }^{1}$ Hailei Kou $\left(D,{ }^{3}\right.$ and Daokai Wei ${ }^{2}$ \\ ${ }^{1}$ School of Highway, Chang'an University, Xi'an, Shanxi 710064, China \\ ${ }^{2}$ School of Highway and Architecture, Shandong Transport Vocational College, Weifang, Shandong 261206, China \\ ${ }^{3}$ College of Engineering, Ocean University of China, Qingdao, Shandong 266100, China
}

Correspondence should be addressed to Hailei Kou; hlkou@ouc.edu.cn

Received 14 January 2020; Revised 2 September 2020; Accepted 11 September 2020; Published 24 September 2020

Academic Editor: Xinyu Ye

Copyright (c) 2020 Jukun Guo et al. This is an open access article distributed under the Creative Commons Attribution License, which permits unrestricted use, distribution, and reproduction in any medium, provided the original work is properly cited.

Surface groove morphology of structure and particle distribution of soil had a significant effect on the surface friction of structure. In order to investigate the interface shear stress-shear displacement curves, interface model and interface shear strength index when normal stress, groove width, and groove angle change, the interface shear tests of standard sand with steel plates are performed using an improved direct shear apparatus. Test results indicate that the peak shear stress increases with normal stress and the intersection angle between groove direction and shear direction. When the angle increases by $45^{\circ}$, the peak shear stress increases range from $4 \%$ to $13 \%$. The peak shear stress increases with groove width, for every $1 \mathrm{~mm}$ increase in groove width, and the increasing extent of peak shear stress ranges from $4 \%$ to $22 \%, 3 \%$ to $13 \%$, and $1 \%$ to $6 \%$, respectively. When the groove angle is $45^{\circ}$ and $90^{\circ}$, the increasing extent of peak shear stress decreases with groove width, but when the groove angle is $0^{\circ}$, the decrease regularity of peak shear stress increasing extent is not obvious. The hyperbolic model and Gompertz-C model are used to study the shear stress-shear displacement curves of sand-steel interface. The ratio of the interface peak shear stress of the hyperbolic model and Gompertz-C model to that of the shear test ranges from 0.90 to 1.03 and 0.88 to 0.98 , respectively. The interface friction angle at the sand-steel interface ranges from $22^{\circ}$ to $29^{\circ}$, and the friction angle of the rough interface is larger than that of the smooth interface. The interface friction angle increases with the intersection angle between the groove direction and the shear direction, the largest at $90^{\circ}$, the second at $45^{\circ}$, and the smallest at $0^{\circ}$. Under the same groove angle, the interface friction angle increases with the groove width, for every $1 \mathrm{~mm}$ increase in groove width, and the increasing extent of interface friction angle ranges from $4 \%$ to $15 \%, 4 \%$ to $7 \%$, and $2 \%$ to $3 \%$, respectively. The increasing extent of interface friction angle decreases with groove width, and this change rule is more obvious at the groove angle of $45^{\circ}$ and $90^{\circ}$ than at $0^{\circ}$.

\section{Introduction}

The interaction at the interface between a structural surface and the surrounding soil surface is often seen in geotechnical engineering applications. A comprehensive understanding of interfacial shear behavior is very important for more accurate analysis and design of different geotechnical structures, such as pile foundation, tunnels, retaining wall, and other structures [1-5]. Thus, the study of shear behavior of structure-soil interface has become an important issue in recent years.

The direct shear test has become an important approach to study the basic laws of shear properties at the interface between structure and soil. The influencing factors and mechanical properties of the interfaces have been studied by a large number of scholars. Potyondy [6] carried out a large number of experiments to characterise the shear behaviour between construction materials and soils. Uesugi and Kishida [7] carried out a series of laboratory tests on the friction between steel and air-dried sands with a simple shear apparatus. Uesugi et al. [8] reported that the sand particles on a rough steel surface rolled as well as slipped along the interface and the movements caused the formation of a shear zone within the sand along the rough interface. Evgin and Fakharian [9] pointed out that the coefficients of friction corresponding to the resultant peak and residual shear 
strengths are independent of the stress paths. Fakharian and Evgin [10] investigated the cyclic behavior of a sand-steel interface under constant normal stress and normal stiffness conditions. The reduction in maximum shear stress was not only due to the reduction in the normal stress, but also due to the increased amount of mobilized sliding displacement with an increasing number of cycles. Gennaro and Frank [11] developed an elastoplastic constitutive model for describing the interface behaviour. Boulon et al. [12] proposed a nonassociated elastoplastic model which used two plastic surfaces for interface behaviour under monotonic and cyclic conditions. Desai et al. [13] proposed a constitutive model based on the disturbed state concept, which can provide a realistic characterization of the interface behavior. Mortara et al. [14] studied the friction characteristics of the sand-steel interfaces and the role of soil deformability on the experimental results. Mortara et al. [15] proposed a simple elastoplastic model for the behavior of smooth sand-steel interfaces. Zhou et al. [16] reported that the thickness of the shear band increases with the normal stress and the shear zone is asymmetrical at the soil-rib interface. Martin et al. [17] found that the shear resistance could be mobilized when the concrete-sand contact area was greater than about $50 \%$ of the total area. Liu et al. [18] indicated that the interface apparent adhesion and friction angle increased with the cyclic shear. Vangla and Latha Gali [19] investigated the effect of particle size of sand and the surface asperity of reinforcing material on their interlocking mechanism and its influence on the interfacial shear strength. Farhadi and Lashkari [20] proposed that the variation in peak friction angle with the bedding plane inclination angle is meaningfully less than that for the same sand. Feng et al. [21] investigated the micromechanical interactions between geomembrane and sand during the shearing process. Khemissa et al. [22] used two elastoplastic behavior models implemented in a finite elements computer program. Martinez et al. [23] studied the interface behavior between two different sands and snakeskin-shape solid surface. The results indicated that the peak and residual interface strength and dilation in the cranial direction were larger than those in the caudal direction.

In the above research, the shape, width, and depth are mainly considered in the fabrication of structure surface groove, and the groove direction is mostly perpendicular to the cutting direction. However, in the actual engineering, the direction of the structure surface groove is disordered, and the angle between groove direction and shear direction can be any angle. Under the same groove volume, it is worth to further study on the characteristics of shear strength and shear index of the interface with different groove directions. Wang et al. [24] placed the grooved structure in the lower box and simulated different roughness by changing the rotation angle and groove depth of the structure, studied the effects of roughness and normal stress on the interface properties. In this article, in order to investigate the interface shear stress-shear displacement curves, interface model and interface shear strength index when normal stress, groove width, and groove angle change, the interface shear tests of sand with steel plates are performed using an improved direct shear apparatus.

\section{Interfacial Shear Test}

2.1. Experimental Device. The direct shear device used in the test is transformed from the strain-controlled direct shear apparatus, as shown in Figure 1. Standard sand and permeable stones are put into the upper shear box, and the volume of standard sand is $30 \mathrm{~cm}^{2} \times 1.5 \mathrm{~cm}$. The lower shear box is finished through mechanical preprocessing, and it is filled with a steel plate, as shown in Figure 2. The lower box of the original direct shear equipment is emptied, and it is put into the processed steel ring(1); the steel ring is fixed with two hexagon bolts(2) and extra strong glue. The structure is placed in the steel ring to ensure that the internal dimension of the steel ring is the same as that of the structure, so that the structure can rotate freely within $360^{\circ}$. The structure is tightly combined with the lower shear box which causes the formation of air pressure, and the test block cannot be taken out, so a circular hole(3) is placed in the center of the bottom of the lower shear box. In order to prevent the structure from rotating during the test, the structure in the lower box is fixed by the hexagon bolt(4) set on the side wall of the shear box. Drill two bolt holes(5) at the diagonal position of the steel ring to place the bolt to connect the upper shear box, so as to ensure that the structure and the soil do not move relatively during the process of adding and preloading the soil sample. Finally, the bolt is taken out before the shear test. Because the space size of the structure placed in the lower shear box is $\Phi 8 \mathrm{~cm} \times 2.5 \mathrm{~cm}$ and the diameter of the soil sample in the upper shear box is $6.18 \mathrm{~cm}$, the distance between the edge of the sand and the edge of the structure is $9.1 \mathrm{~mm}$, and it is possible to ensure that the contact area between sand and structure remains unchanged during the test.

2.2. Experimental Material. The standard sand used in the test is produced by the Xiamen ISO Standard Sand Co., Ltd. company, which manufactured according to GB/T 176711999. The particle size distribution curve of standard sand in the test is shown in Figure 3. Fine sand with particle size ranges from 0.075 to $0.15 \mathrm{~mm}$ is selected as the test sand, as shown in Figure 4 . The basic physical and mechanical indexes of standard sand are obtained according to the standard for soil test method (GB/T 50123-2019), as shown in Table 1.

The steel plate used in the test is made up of stainless steel by mechanical processing. Front and elevation view of the steel plate are shown in Figures 5 and 6. The steel plate is $8 \mathrm{~cm}$ in diameter and $2.5 \mathrm{~cm}$ in height. There are four steel plates in total, one with smooth surface is defined as Int-A, and the other three are machined into a rough surface with 7 grooves by mechanical equipment. The groove shape of the steel plate is an inverted triangle with a depth of $2 \mathrm{~mm}$ and a width of $1 \mathrm{~mm}, 2 \mathrm{~mm}$, and $3 \mathrm{~mm}$, respectively. According to the width from small to large, it is defined as Int-B, Int-C, and Int-D. As mentioned before, the steel plate used in the test can rotate $360^{\circ}$ in the lower shear box. In order to study the influence of groove direction on the interface shear characteristics, it is specified that the groove angle is $0^{\circ}$ when 


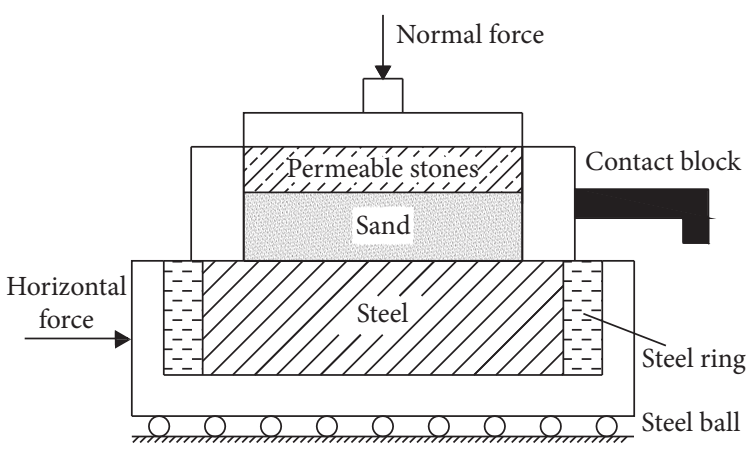

FIGURE 1: Improved direct shear apparatus sketch.

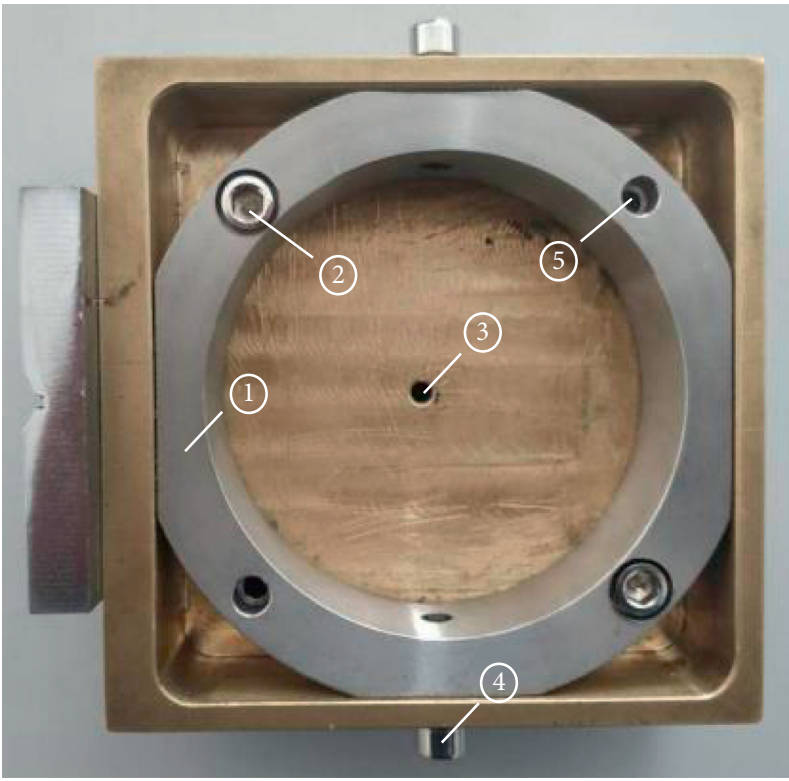

(a)

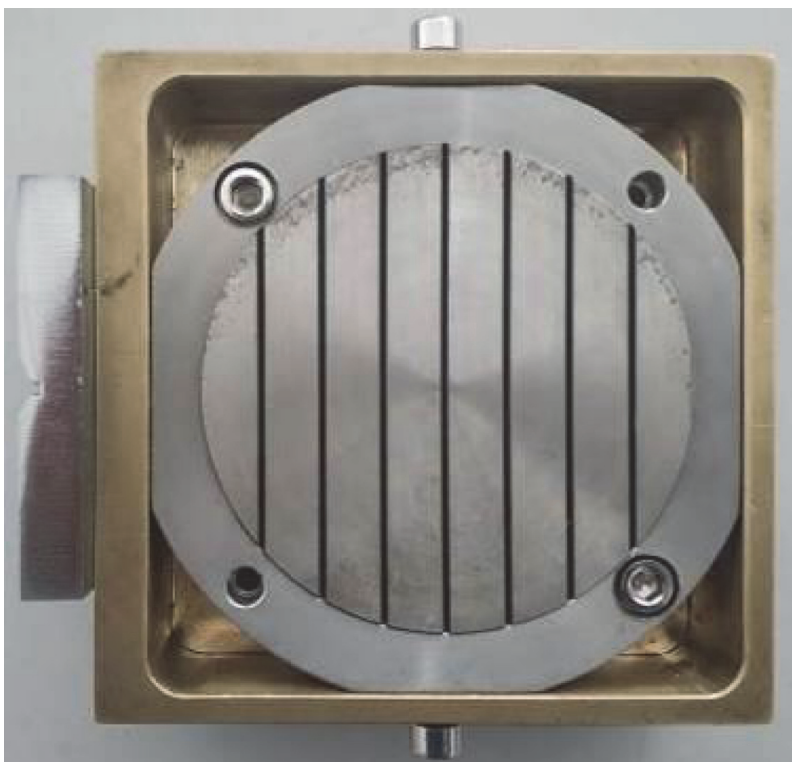

(b)

Figure 2: (a) (1) Steel ring; (2) connecting bolts for fixing the steel ring and lower shear box; (3) circular hole at the bottom of the lower box; (4) bolts for fixing the structure in the lower box; (5) bolt hole for connecting the upper shear box. (b) Lower shear box for direct shear apparatus.

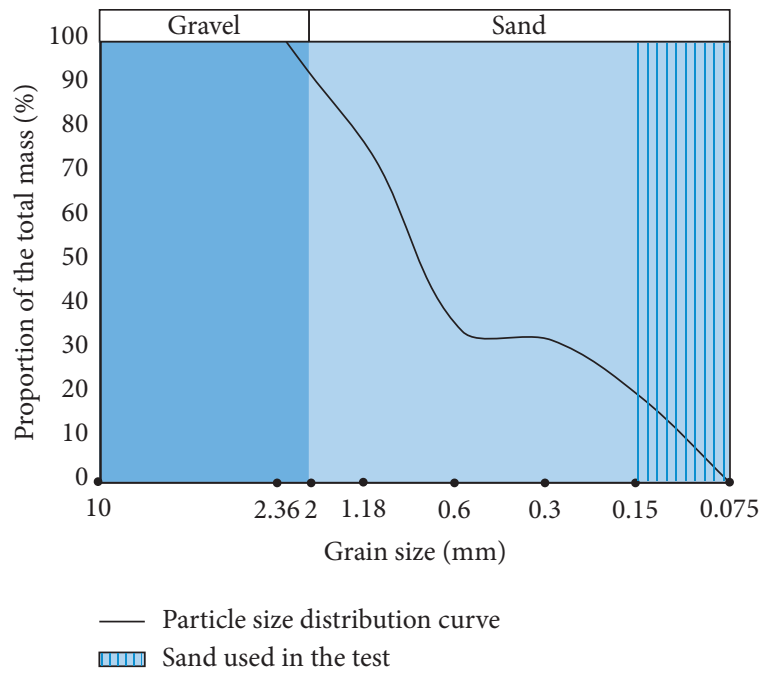

Figure 3: Particle size distribution curve of sand in the test. the groove direction is the same as the shear direction. When the steel plate rotates clockwise, the groove angle is defined as a positive value. In this test, the groove angle is selected as $0^{\circ}, 45^{\circ}$, and $90^{\circ}$ for research, respectively, Int-D is taken as an example, as shown in Figure 7.

2.3. Experimental Scheme. Four kinds of steel plates are put with different surface morphology into the lower shear box, respectively, the sand after oven drying and permeable stone are placed into the upper shear box, and in turn, the quality of standard sand and prepressing time is the same for each test. The vertical dial indicator is zeroed after prepressing $10 \mathrm{~min}$ at normal stress for each test, and then shear tests were carried out under normal stress of $50 \mathrm{kPa}, 100 \mathrm{kPa}, 150 \mathrm{kPa}$, and $200 \mathrm{kPa}$. There are 40 groups of interfacial shear tests. The displacement control loading method is adopted in the test, and the shear rate is set at $0.8 \mathrm{~mm} / \mathrm{min}$. 


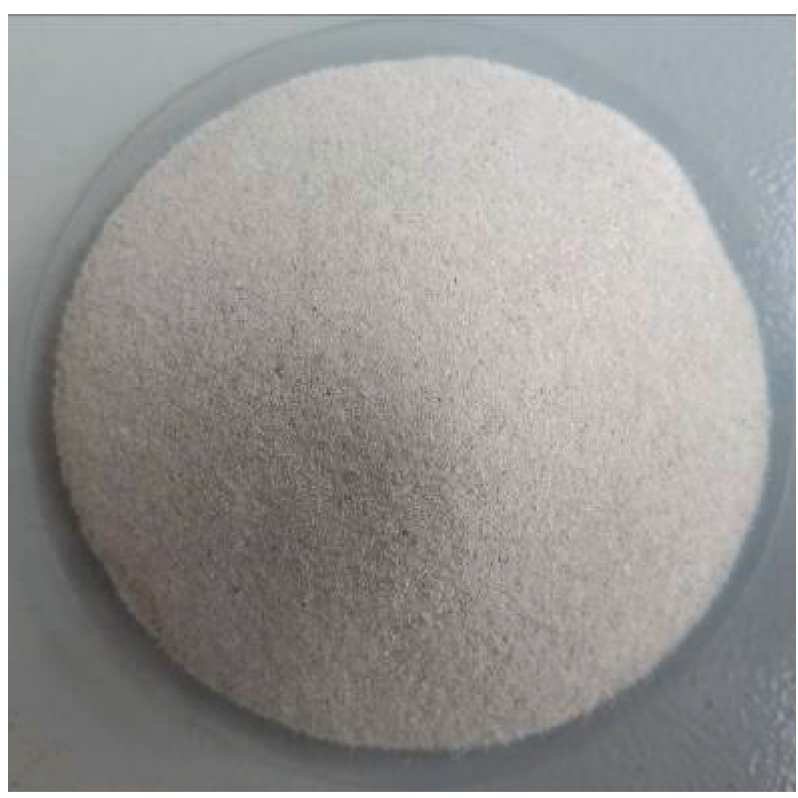

Figure 4: Sand used in the test.

TABle 1: Physical and mechanical properties of sand.

\begin{tabular}{lcccccc}
\hline$d_{50}(\mathrm{~mm})$ & $e_{\max }$ & $e_{\max }$ & $e$ & $G_{s}$ & $\rho\left(\mathrm{g} \cdot \mathrm{cm}^{-3}\right)$ & $\Phi\left({ }^{\circ}\right)$ \\
\hline 0.11 & 0.647 & 0.886 & 0.808 & 2.64 & 1.46 & 31.6 \\
\hline
\end{tabular}

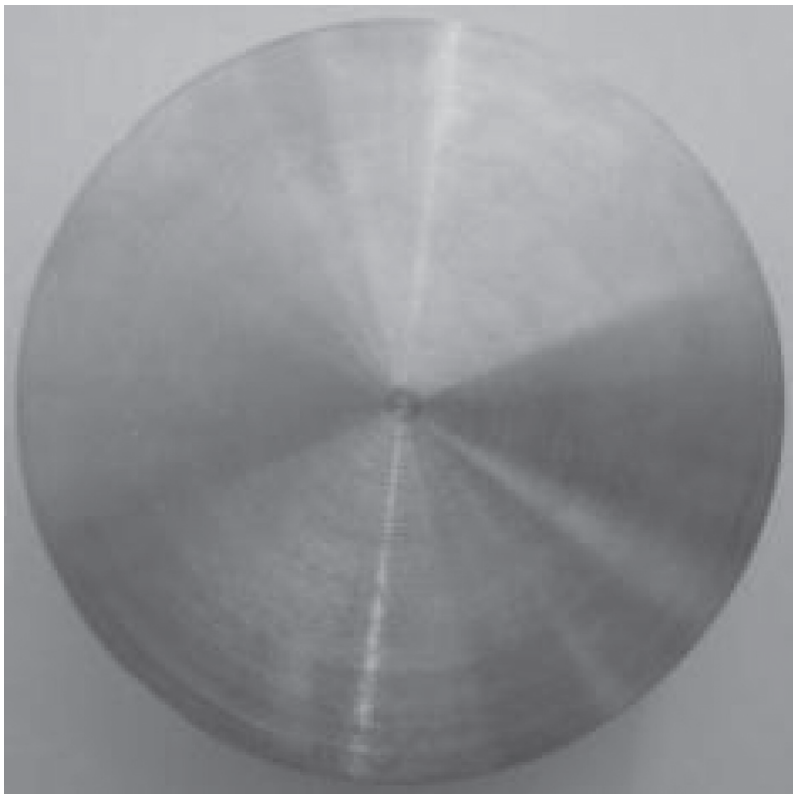

(a)

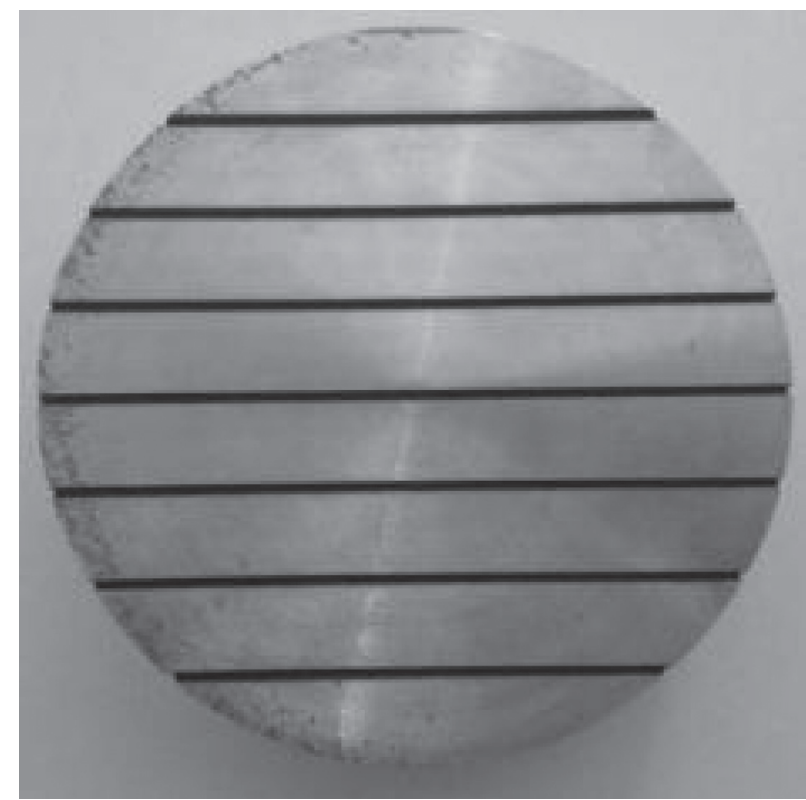

(b)

FIgURE 5: Continued. 


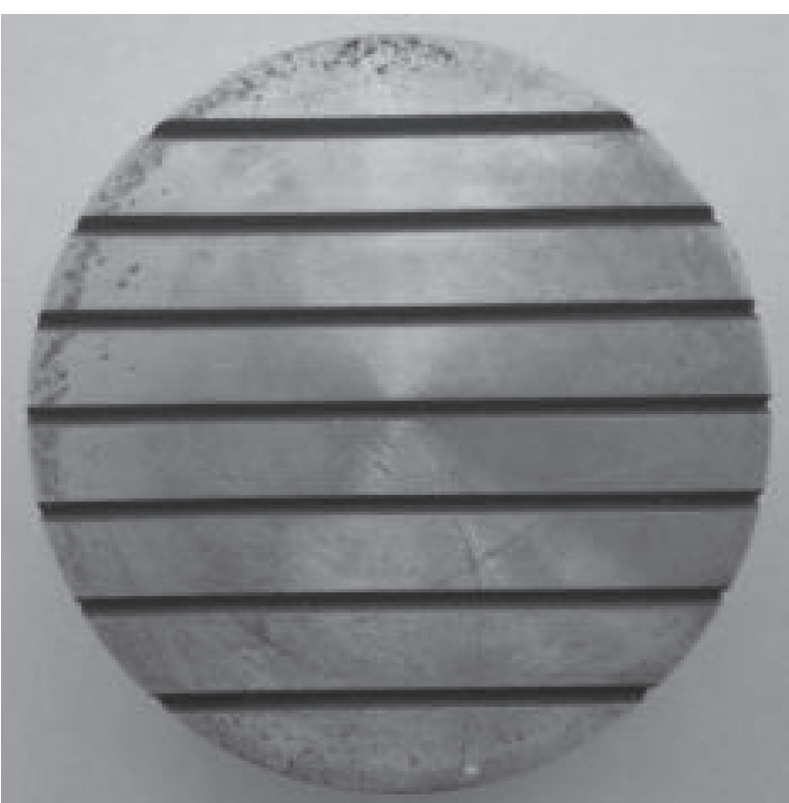

(c)

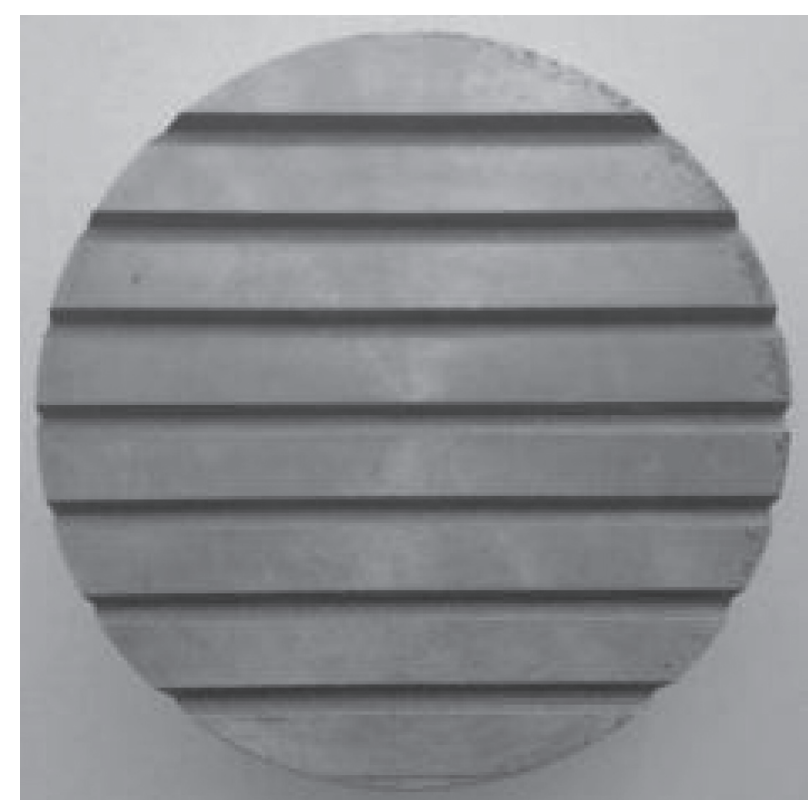

(d)

FIgUre 5: Front view of the steel plate used in the test. (a) Int-A; (b) Int-B; (c) Int-C; (d) Int-D.

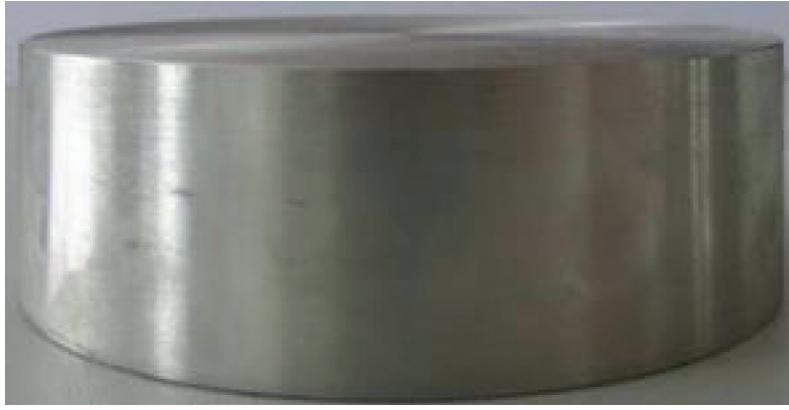

(a)

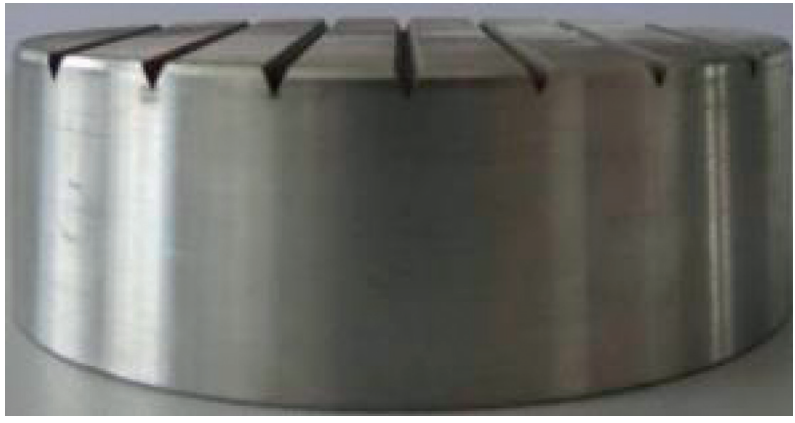

(c)

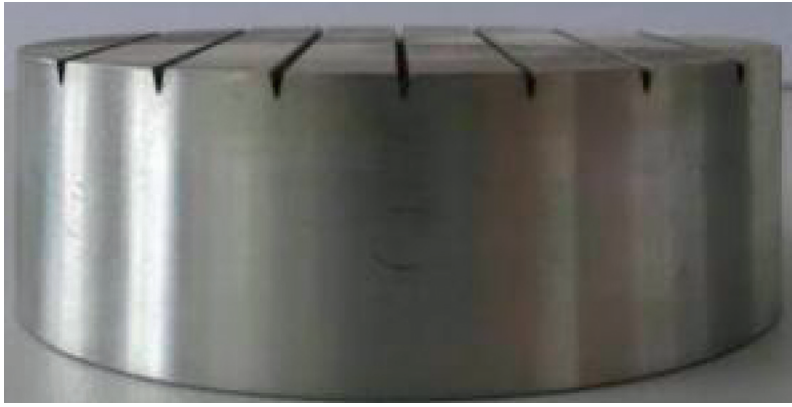

(b)

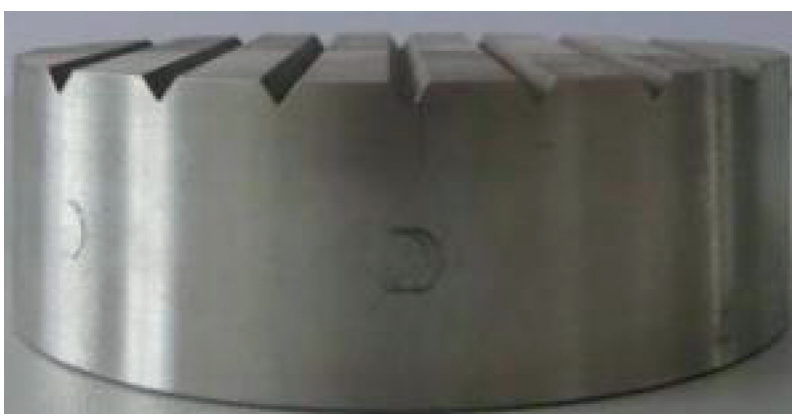

(d)

Figure 6: Elevation of the steel plate used in the test. (a) Int-A; (b) Int-B; (c) Int-C; (d) Int-D.

\section{Test Results and Discussion}

3.1. ShearStress-Displacement Relationship. The shear stressshear displacement curves for the steel-sand interfaces are shown in Figure 8. The peak shear stress-groove width relationships for the steel-sand interfaces is shown in Figure 9. Increasing extent of peak shear stress with groove angle is shown in Table 2. The increasing extents of peak shear stress with groove width are shown in Table 3 . The results include the following: the shear stress increases with shear displacement, and the increasing speed is faster; then, the increasing speed decreases with shear displacement until it reaches the peak shear stress; then, the shear stress softens slightly and fluctuates slightly. The peak shear stress and 


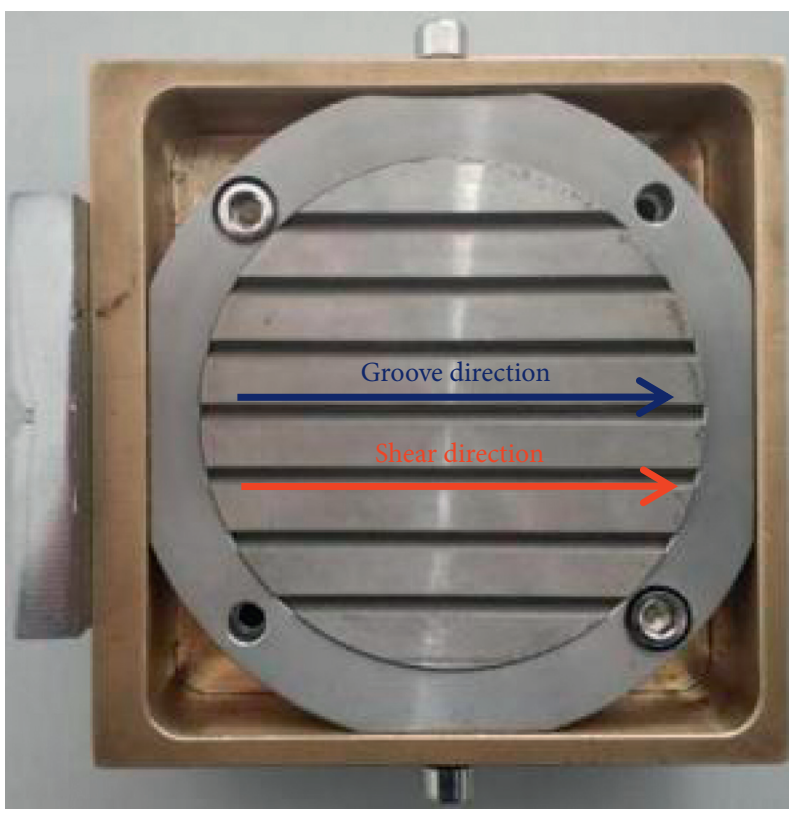

(a)

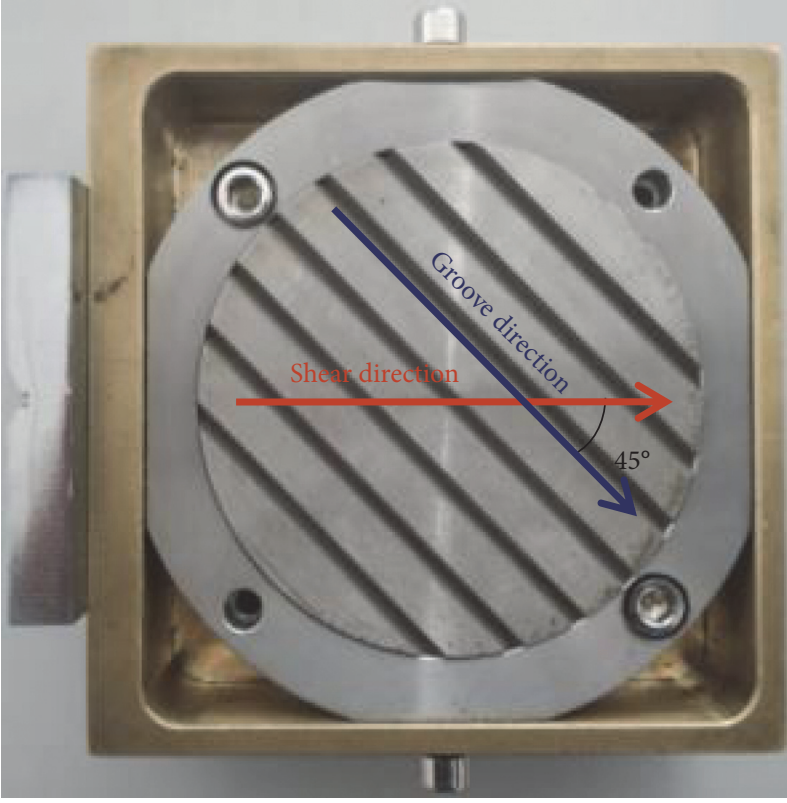

(b)

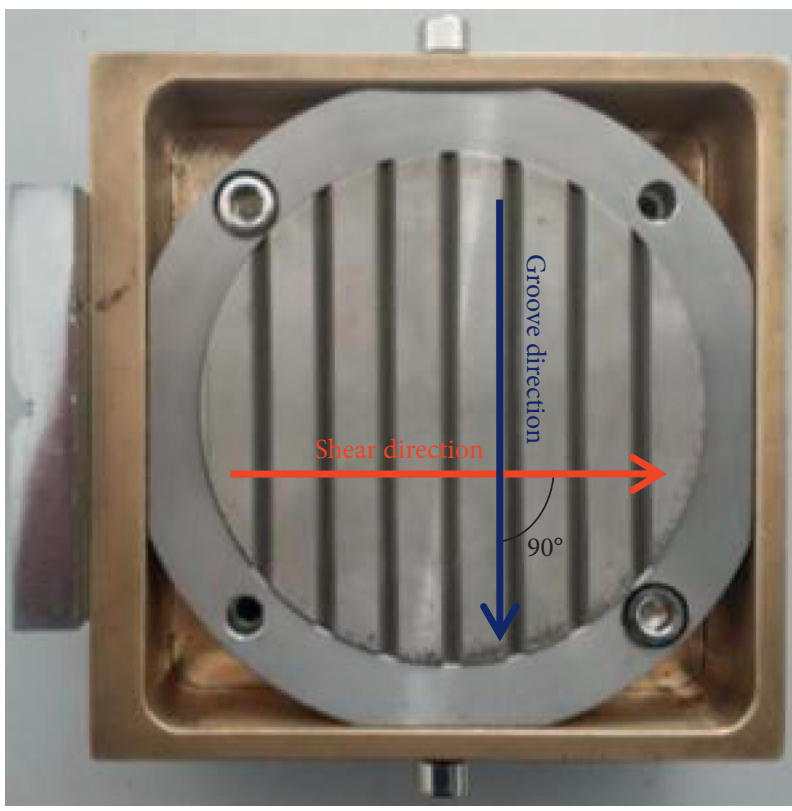

(c)

FIGURE 7: Groove angle of interface $D$. (a) $0^{\circ}$; (b) $45^{\circ}$; (c) $90^{\circ}$.

peak shear displacement increase with normal stress. The peak shear stress of Int-B, Int- $C$, and Int-D is much larger than that of Int-A, which indicates that the surface morphology has an effect on the shear strength. Under the same groove shape and size, the peak shear stress increases with normal stress and the angle between groove direction and shear direction. As shown in Table 2, A represents the increasing extent of peak shear stress from $0^{\circ}$ to $45^{\circ}$, which ranges from $4 \%$ to $13 \%$, and $\mathrm{B}$ represents the increasing extent of peak shear stress from $45^{\circ}$ to $90^{\circ}$, which ranges from $4 \%$ to $12 \%$. The above data show that the groove direction is the influencing factor of the interface shear characteristics under the same groove volume, so the roughness of the interface cannot be evaluated simply by the groove volume. As shown in Figure 9, the groove width of Int-A is taken as $0 \mathrm{~mm}$ and the peak shear stress of Int- $\mathrm{A}$ is the same at any rotation angle. Under the same groove angle, the peak shear stress increases with the groove width. $C, D$, and $E$ represent the increasing extent of peak shear stress from $0 \mathrm{~mm}$ to $1 \mathrm{~mm}, 1 \mathrm{~mm}$ to $2 \mathrm{~mm}$, and $2 \mathrm{~mm}$ to $3 \mathrm{~mm}$. The corresponding value of $C, D$, and $E$ ranges from $4 \%$ to $22 \%, 3 \%$ to $13 \%$, and $1 \%$ to $6 \%$, respectively. When the groove angle is 

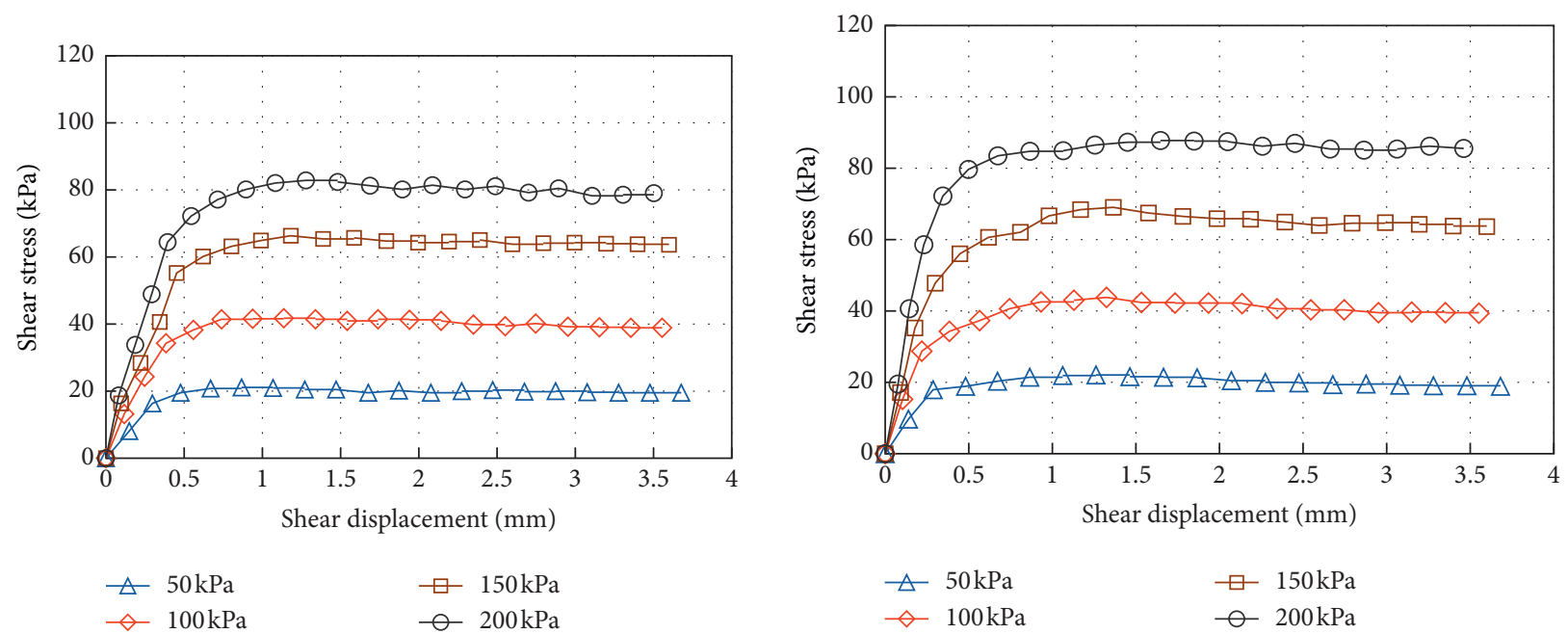

$$
\triangle 50 \mathrm{kPa} \quad \square 150 \mathrm{kPa}
$$

(a)

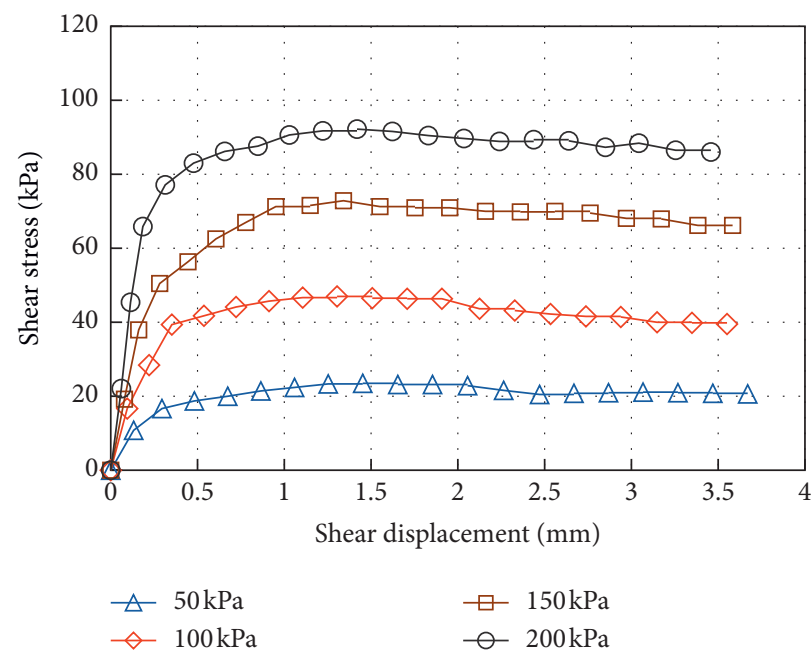

(c)

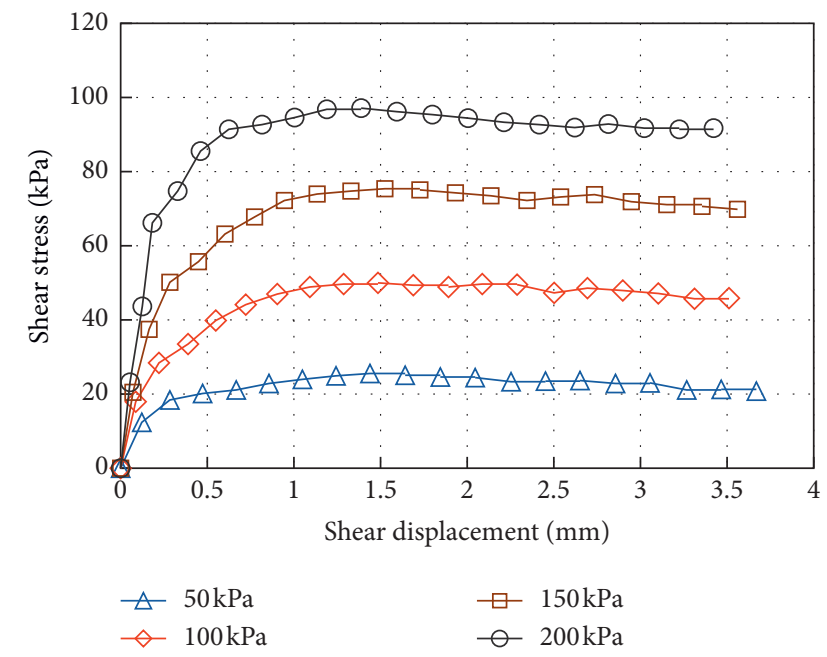

(d)
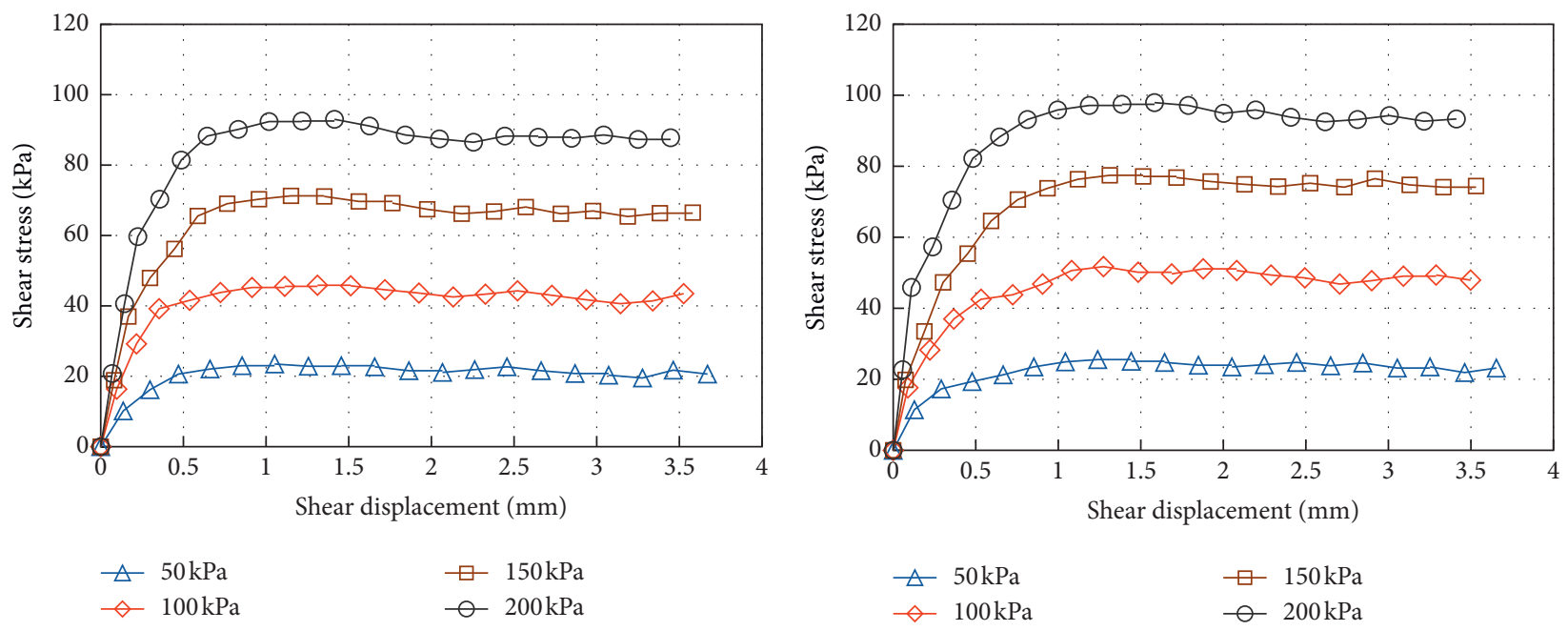

(e)

(f)

Figure 8: Continued. 

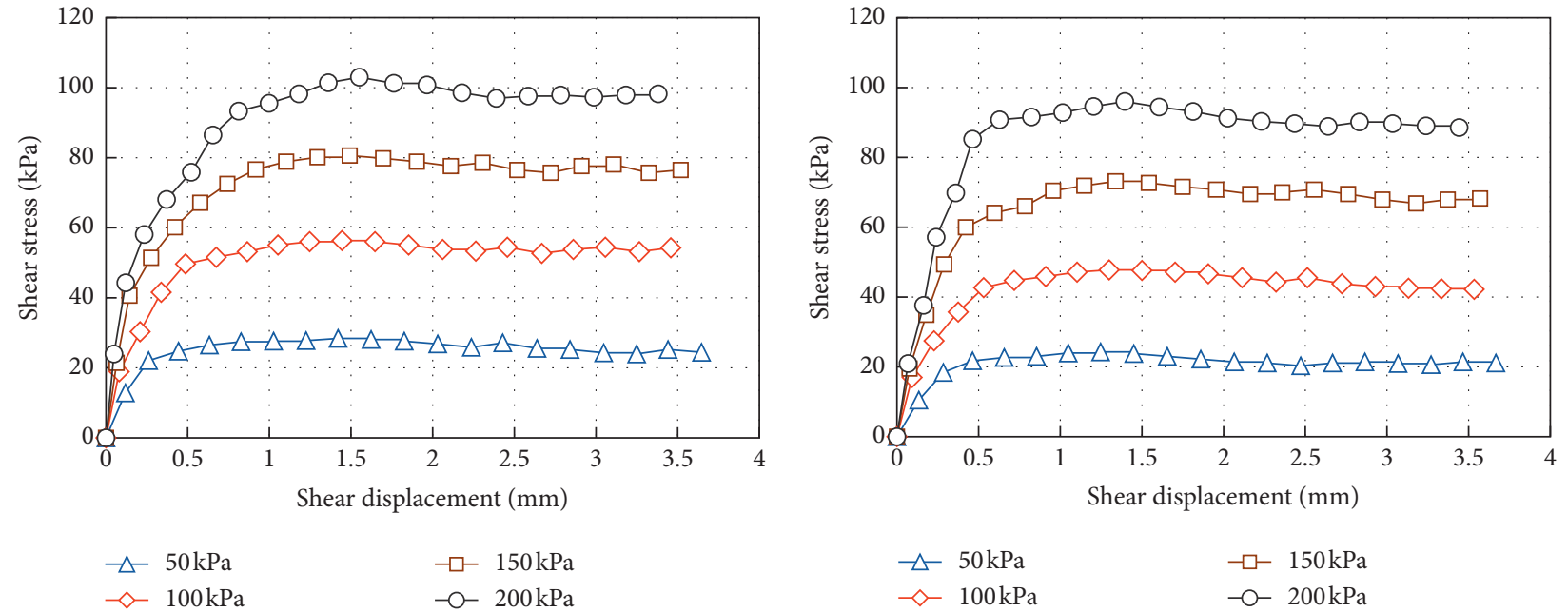

(g)

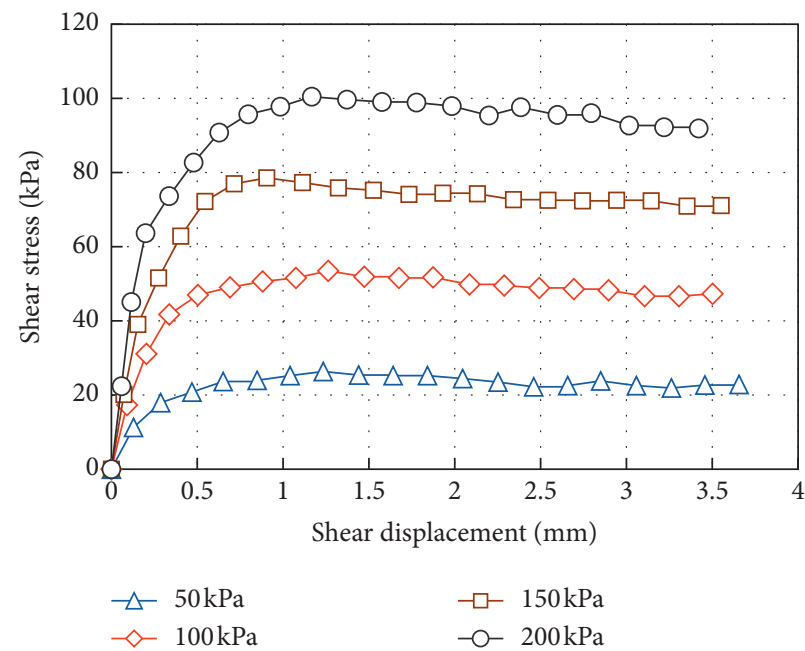

(i)

(h)

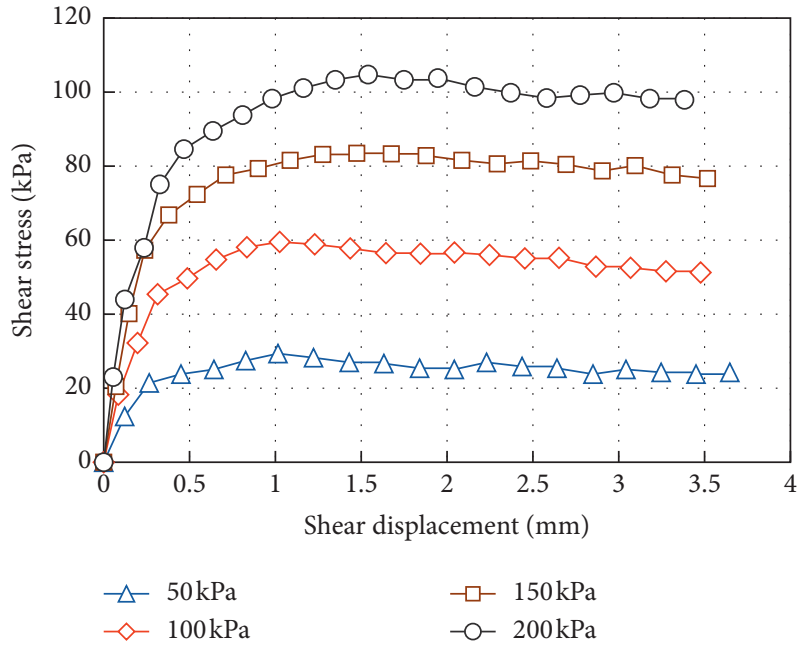

(j)

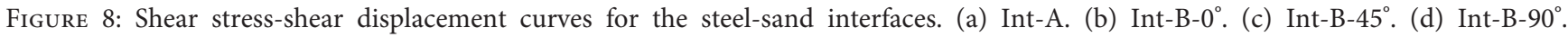

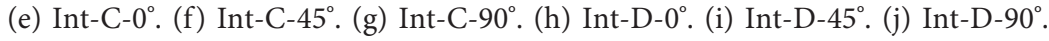
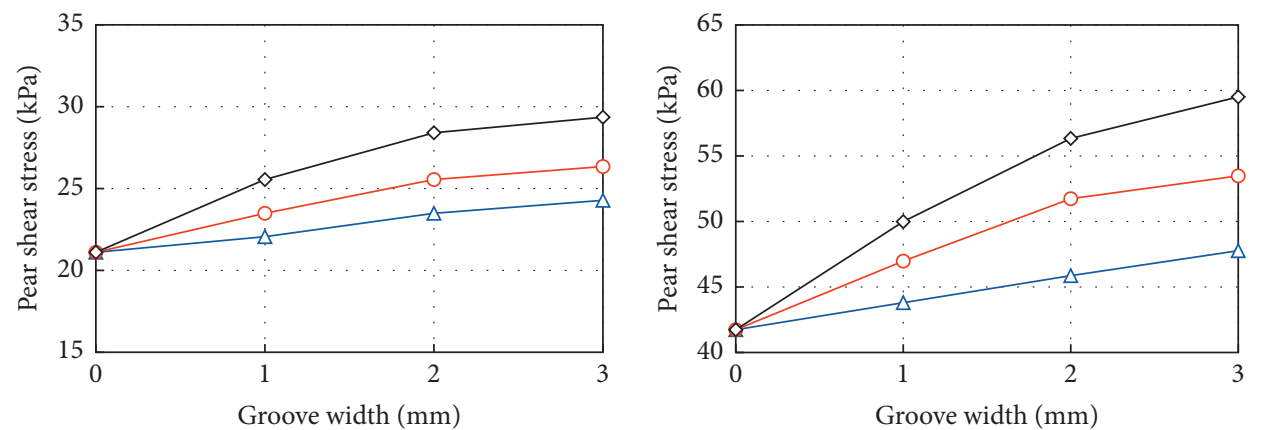

$$
\begin{array}{ll}
-\neg 0^{\circ} & -\neg 0^{\circ} \\
-\circ 45^{\circ} & -\circ 45^{\circ} \\
\multimap-90^{\circ} & \multimap-90^{\circ}
\end{array}
$$

(a)

(b)

Figure 9: Continued. 


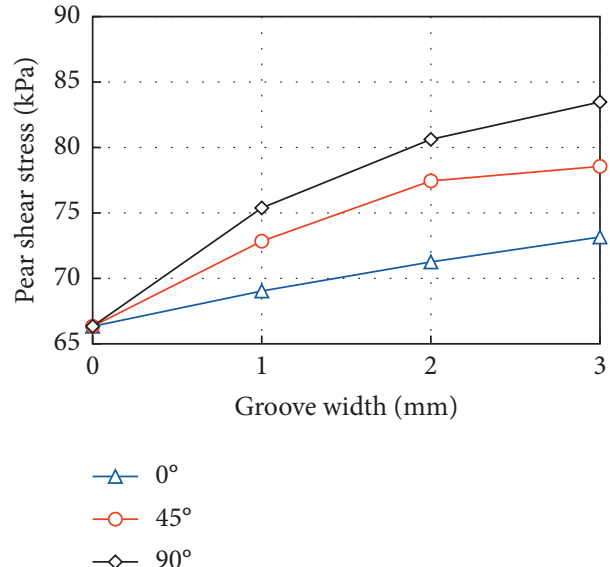

(c)

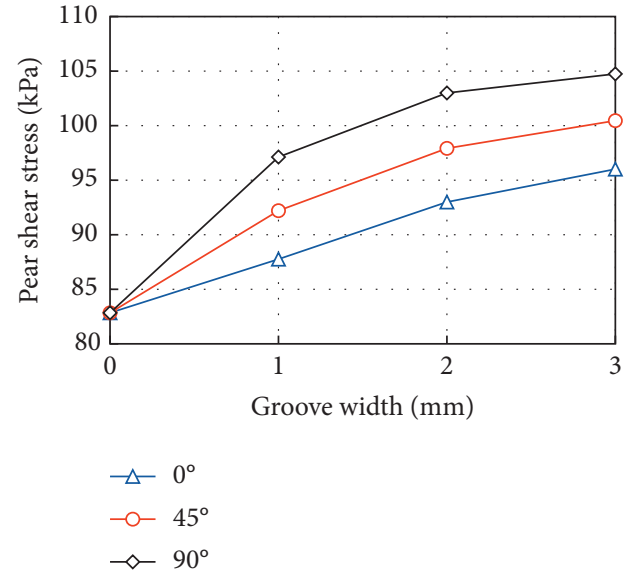

(d)

Figure 9: Peak shear stress-groove width relationship for the steel-sand interfaces. (a) $50 \mathrm{kPa}$. (b) $100 \mathrm{kPa}$. (c) $150 \mathrm{kPa}$. (d) $200 \mathrm{kPa}$.

TABLE 2: Increasing extent of peak shear stress with groove angle.

\begin{tabular}{|c|c|c|c|c|c|c|}
\hline \multirow{2}{*}{ Interface } & \multirow{2}{*}{$\sigma_{n}(\mathrm{kPa})$} & \multicolumn{3}{|c|}{ Groove angle $\left({ }^{\circ}\right)$} & \multirow{2}{*}{$A(\%)$} & \multirow{2}{*}{$B(\%)$} \\
\hline & & 0 & 45 & 90 & & \\
\hline \multirow{4}{*}{ Int-B } & 50 & 22.06 & 23.49 & 25.55 & 6.5 & 8.8 \\
\hline & 100 & 43.80 & 46.98 & 49.99 & 7.2 & 6.4 \\
\hline & 150 & 69.03 & 72.84 & 75.38 & 5.5 & 3.5 \\
\hline & 200 & 87.76 & 92.20 & 97.12 & 5.1 & 5.3 \\
\hline \multirow{4}{*}{ Int-C } & 50 & 23.49 & 25.55 & 28.41 & 8.8 & 11.2 \\
\hline & 100 & 45.86 & 51.74 & 56.34 & 12.8 & 8.9 \\
\hline & 150 & 71.26 & 77.45 & 80.62 & 8.7 & 4.1 \\
\hline & 200 & 93.00 & 97.92 & 103.00 & 5.3 & 5.2 \\
\hline \multirow{4}{*}{ Int-D } & 50 & 24.28 & 26.34 & 29.36 & 8.5 & 11.4 \\
\hline & 100 & 47.77 & 53.48 & 59.51 & 12.0 & 11.3 \\
\hline & 150 & 73.16 & 78.56 & 83.48 & 7.4 & 6.3 \\
\hline & 200 & 96.01 & 100.46 & 104.74 & 4.6 & 4.3 \\
\hline
\end{tabular}

TABLE 3: Increasing extent of peak shear stress with groove width.

\begin{tabular}{|c|c|c|c|c|c|c|c|c|}
\hline \multirow{2}{*}{$\sigma_{n}(\mathrm{kPa})$} & \multirow{2}{*}{ Groove angle $\left(^{\circ}\right)$} & \multicolumn{4}{|c|}{ Groove width $(\mathrm{mm})$} & \multirow{2}{*}{$C(\%)$} & \multirow{2}{*}{$D(\%)$} & \multirow{2}{*}{$E(\%)$} \\
\hline & & 0 & 1 & 2 & 3 & & & \\
\hline \multirow{3}{*}{50} & 0 & 21.11 & 22.06 & 23.49 & 24.28 & 4.5 & 6.5 & 3.4 \\
\hline & 45 & 21.11 & 23.49 & 25.55 & 26.34 & 11.3 & 8.8 & 3.1 \\
\hline & 90 & 21.11 & 25.55 & 28.41 & 29.36 & 21.1 & 11.2 & 3.4 \\
\hline \multirow{3}{*}{100} & 0 & 41.74 & 43.80 & 45.86 & 47.77 & 4.9 & 4.7 & 4.2 \\
\hline & 45 & 41.74 & 46.98 & 51.74 & 53.48 & 12.5 & 10.1 & 3.4 \\
\hline & 90 & 41.74 & 49.99 & 56.34 & 59.51 & 19.8 & 12.7 & 5.6 \\
\hline \multirow{3}{*}{150} & 0 & 66.34 & 69.03 & 71.26 & 73.16 & 4.1 & 3.2 & 2.7 \\
\hline & 45 & 66.34 & 72.84 & 77.45 & 78.56 & 9.8 & 6.3 & 1.4 \\
\hline & 90 & 66.34 & 75.38 & 80.62 & 83.48 & 13.6 & 6.9 & 3.5 \\
\hline \multirow{3}{*}{200} & 0 & 82.84 & 87.76 & 93.00 & 96.01 & 5.9 & 6.0 & 3.2 \\
\hline & 45 & 82.84 & 92.20 & 97.92 & 100.46 & 11.3 & 6.2 & 2.6 \\
\hline & 90 & 82.84 & 97.12 & 103.00 & 104.74 & 17.2 & 6.0 & 1.7 \\
\hline
\end{tabular}

$45^{\circ}$ and $90^{\circ}$, the increasing extent of peak shear stress decreases with the increase of groove width, but when the groove angle is $0^{\circ}$, the decrease regularity of peak shear stress increasing extent is not obvious.
3.2. Interface Model. It is an important research aspect to find a reasonable mathematical model to describe the shear stress-shear displacement relationship of the soil-structure interface. The correct and reasonable interface mathematical 


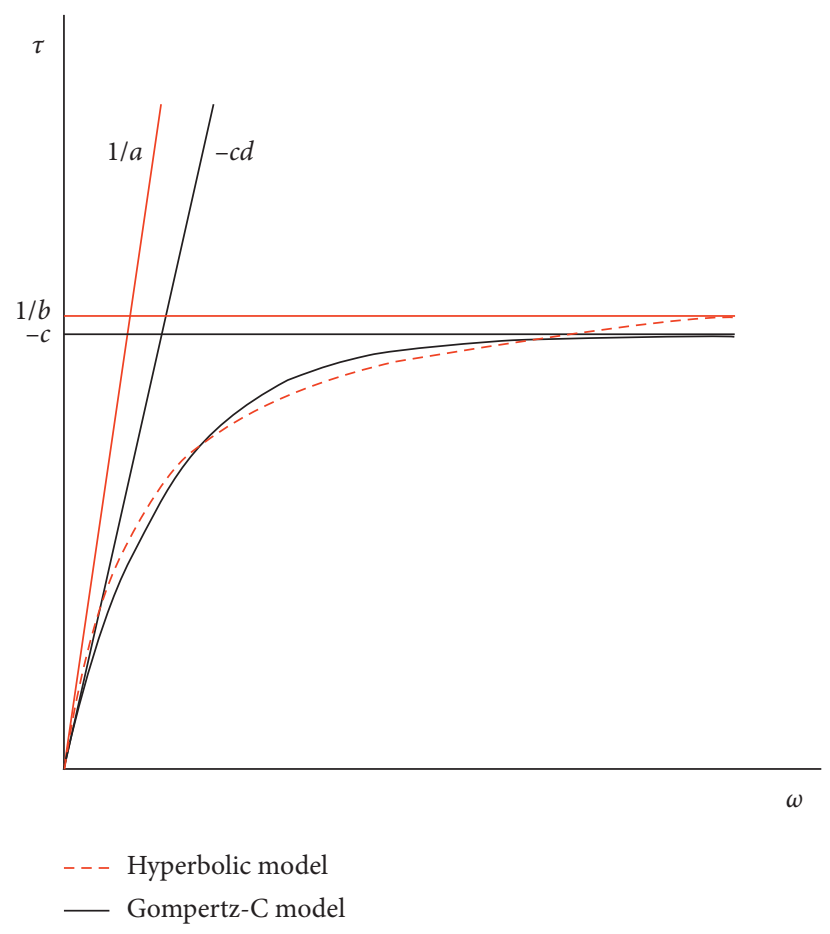

FIgURE 10: Schematic diagram of the interface model.

TABle 4: Parameters of the interface mathematical model.

\begin{tabular}{|c|c|c|c|c|c|}
\hline \multirow{2}{*}{ Interface } & \multirow{2}{*}{ Normal stress $(\mathrm{kPa})$} & \multicolumn{2}{|c|}{ Hyperbolic model } & \multicolumn{2}{|c|}{ Gompertz-C model } \\
\hline & & $a$ & $b$ & $c$ & $d$ \\
\hline \multirow{4}{*}{ Int- $A$} & 50 & 0.0054 & 0.0467 & -20.20 & 4.882 \\
\hline & 100 & 0.0034 & 0.0229 & -40.65 & 4.177 \\
\hline & 150 & 0.0029 & 0.0139 & -65.23 & 3.282 \\
\hline & 200 & 0.0022 & 0.0112 & -81.18 & 3.508 \\
\hline \multirow{4}{*}{ Int-D $\left(0^{\circ}\right)$} & 50 & 0.0039 & 0.0431 & -22.12 & 5.764 \\
\hline & 100 & 0.0027 & 0.0207 & -45.25 & 4.541 \\
\hline & 150 & 0.0020 & 0.0132 & -70.19 & 4.158 \\
\hline & 200 & 0.0016 & 0.0100 & -92.22 & 4.101 \\
\hline \multirow{4}{*}{ Int-D $\left(45^{\circ}\right)$} & 50 & 0.0044 & 0.0400 & -23.90 & 4.896 \\
\hline & 100 & 0.0022 & 0.0189 & -49.91 & 5.030 \\
\hline & 150 & 0.0016 & 0.0126 & -74.33 & 4.775 \\
\hline & 200 & 0.0013 & 0.0096 & -96.38 & 4.854 \\
\hline \multirow{4}{*}{ Int-D $\left(90^{\circ}\right)$} & 50 & 0.0033 & 0.0368 & -25.91 & 5.871 \\
\hline & 100 & 0.0021 & 0.0168 & -55.72 & 4.852 \\
\hline & 150 & 0.0016 & 0.0115 & -80.85 & 4.657 \\
\hline & 200 & 0.0015 & 0.0091 & -100.60 & 4.022 \\
\hline
\end{tabular}

model is of great significance to the simulation of soilstructure interaction. At present, the existing interface mathematical models include hyperbolic model [25], rigid plastic model [26], damage model [27], elastic-plastic model [28], and so on. The hyperbolic model is proposed by Clough and Duncan, which describes the interface shear stress-shear displacement relationship. The calculation formula is as follows:

$$
\tau=\frac{w}{(a+b w)}
$$

where $a$ is the reciprocal of the initial shear stiffness, and $b$ is the reciprocal of the ultimate shear stress.

The mathematical equation of Gompertz curve was first proposed by British mathematician and statistician B. Gompertz in 1825 . The equation is as follows:

$$
y=c e^{-d e^{-e x}}
$$

In the above formula, $c, d$, and $e$ are fitting parameters, $x$ is independent variable, and $y$ is dependent variable. Because there are three parameters in the formula, it is more 
TABLE 5: Interface pear shear stress of the mathematical model and test (kPa).

\begin{tabular}{|c|c|c|c|c|c|c|c|}
\hline Interface & Normal stress $(\mathrm{kPa})$ & $\tau_{f}$ & $\tau_{u}$ & $\tau_{m}$ & $\tau_{u} / \tau_{f}$ & $\tau_{m} / \tau_{f}$ & $\tau_{u} / \tau_{m}$ \\
\hline \multirow{4}{*}{ Int- $A$} & 50 & 21.11 & 20.76 & 20.20 & 0.98 & 0.96 & 1.03 \\
\hline & 100 & 41.74 & 41.92 & 40.65 & 1.00 & 0.97 & 1.03 \\
\hline & 150 & 66.34 & 68.00 & 65.23 & 1.03 & 0.98 & 1.04 \\
\hline & 200 & 82.84 & 84.54 & 81.18 & 1.02 & 0.98 & 1.04 \\
\hline \multirow{4}{*}{ Int-D $\left(0^{\circ}\right)$} & 50 & 24.28 & 22.59 & 22.12 & 0.93 & 0.91 & 1.02 \\
\hline & 100 & 47.77 & 46.59 & 45.25 & 0.98 & 0.95 & 1.03 \\
\hline & 150 & 73.16 & 72.67 & 70.19 & 0.99 & 0.96 & 1.04 \\
\hline & 200 & 96.01 & 95.56 & 92.22 & 1.00 & 0.96 & 1.04 \\
\hline \multirow{4}{*}{ Int-D $\left(45^{\circ}\right)$} & 50 & 26.34 & 24.51 & 23.90 & 0.93 & 0.91 & 1.03 \\
\hline & 100 & 53.48 & 51.47 & 49.91 & 0.96 & 0.93 & 1.03 \\
\hline & 150 & 78.56 & 76.63 & 74.33 & 0.98 & 0.95 & 1.03 \\
\hline & 200 & 100.46 & 100.20 & 96.38 & 1.00 & 0.96 & 1.04 \\
\hline \multirow{4}{*}{ Int-D $\left(90^{\circ}\right)$} & 50 & 29.36 & 26.52 & 25.91 & 0.90 & 0.88 & 1.02 \\
\hline & 100 & 59.51 & 57.46 & 55.72 & 0.97 & 0.94 & 1.03 \\
\hline & 150 & 83.48 & 83.65 & 80.85 & 1.00 & 0.97 & 1.03 \\
\hline & 200 & 104.74 & 104.78 & 100.60 & 1.00 & 0.96 & 1.04 \\
\hline
\end{tabular}

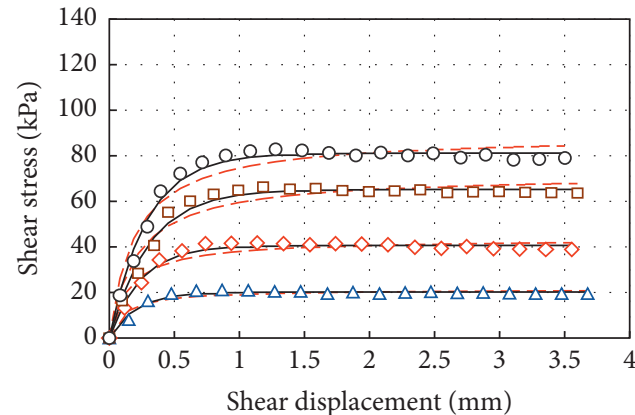

\begin{tabular}{|c|c|}
\hline $50 \mathrm{kPa}$ & __ Gompertz-C model \\
\hline $100 \mathrm{kPa}$ & -- - Hyperbolic model \\
\hline $150 \mathrm{kPa}$ & \\
\hline
\end{tabular}

(a)

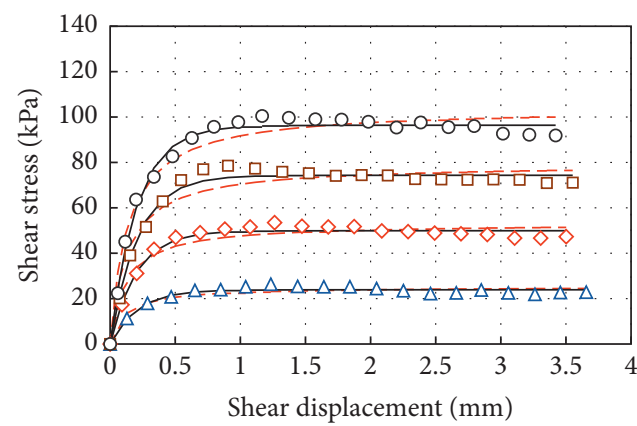
$\triangle 50 \mathrm{kPa}$
- Gompertz-C model
$\diamond 100 \mathrm{kPa}$
- - Hyperbolic model
口 $150 \mathrm{kPa}$
○ $200 \mathrm{kPa}$

(c)

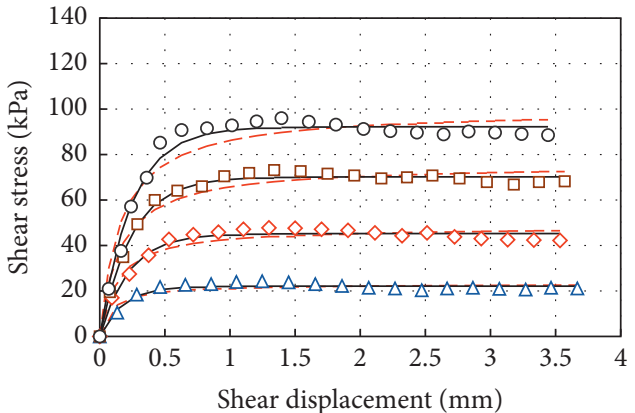
$\triangle 50 \mathrm{kPa}$
- Gompertz-C model
$\diamond 100 \mathrm{kPa}$
- - - Hyperbolic model
口 $150 \mathrm{kPa}$
- $200 \mathrm{kPa}$

(b)

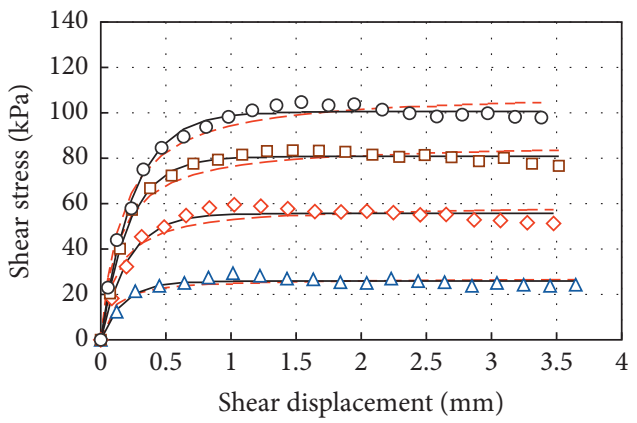
$\triangle 50 \mathrm{kPa}$
_ Gompertz-C model
$\diamond 100 \mathrm{kPa}$
- - - Hyperbolic model
$150 \mathrm{kPa}$
○ $200 \mathrm{kPa}$

(d)

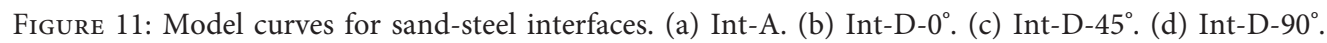




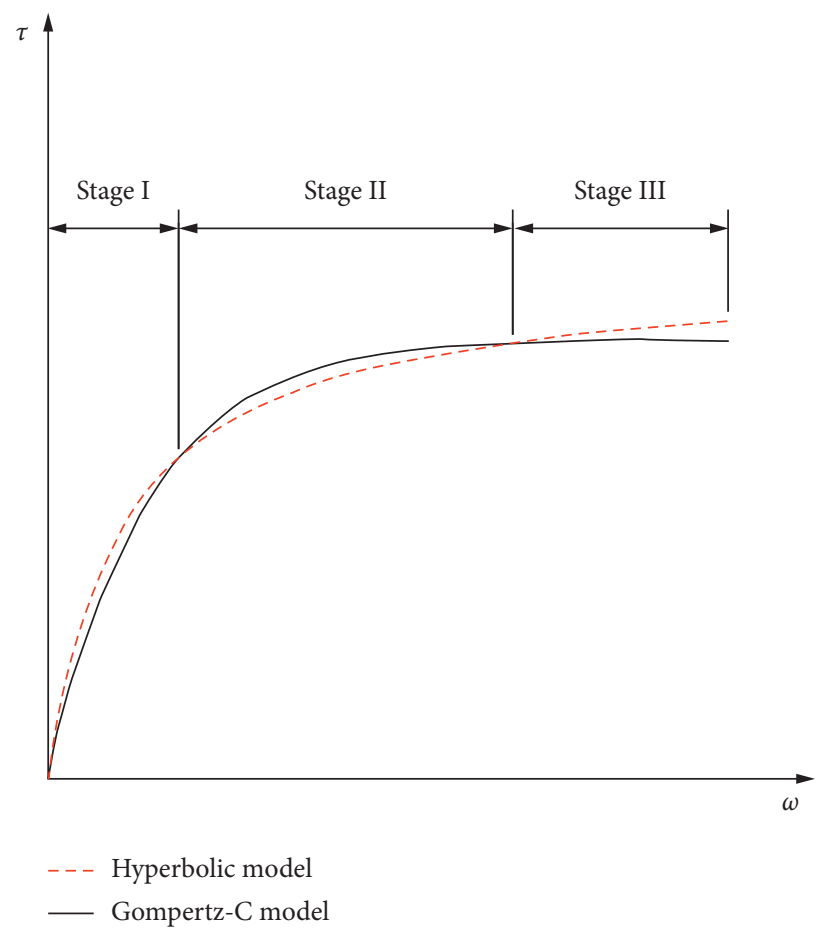

Figure 12: Three stages of the interface model.

complicated to determine, and the curve of the Gompertz mathematical model is S-shaped, which is different from the interface shear stress-shear displacement curve. In addition, the shear stress-shear displacement curve passes through the origin of coordinates, so formula (1) is modified. The transformation form of the Gompertz mathematical model is obtained by changing- $\mathrm{d} e^{-e x}$ to $-\mathrm{d} x$, and the coefficient $c$ is subtracted from the $\mathrm{y}$-axis, which is named Gompertz-C. In this paper, $x$ is the shear displacement, denoted by the symbol $\omega$, and $y$ is the shear stress, denoted by $\tau$. The model formula is

$$
\tau=c\left(e^{-d \omega}-1\right)
$$

The schematic diagram of the Gompertz-C model is shown in Figure 10, where $-c$ is the extreme value of the curve's ordinate and $-c d$ is the starting slope.

In this paper, the hyperbolic model and Gompertz- $\mathrm{C}$ model are used to study the shear stress-shear displacement curves of sand-steel interfaces, and the parameters and fitting data of the two models are compared. Limited by the length of this paper, only In-A and Int-D are selected for research.

Table 4 illustrates parameters of the hyperbolic model and Gompertz-C model. Table 5 shows interface peak shear stress of the hyperbolic model and Gompertz- $\mathrm{C}$ model and compares them with the test peak shear stress. In Table 5, $\tau_{f}$ is the peak shear stress of the test, $\tau_{u}$ is the peak shear stress of the hyperbolic model, and $\tau_{m}$ is the peak shear stress of the Gompertz-C model. The curves of sand-steel interface fitted by the hyperbolic model and Gompertz-C model are presented in Figure 11 and compare them with the experimental data. It can be obtained that the change rule of peak shear stress of the model is the same as that of test shear stress. The interface peak shear stress of the hyperbolic model is larger than that of the Gompertz-C model. The calculation results show that the ratio of the interface peak shear stress of the hyperbolic model to that of the Gompertz- $\mathrm{C}$ model ranges from 1.02 to 1.04 . The ratio of the interface peak shear stress of the hyperbolic model and Gompertz-C model to that of the shear test ranges from 0.90 to 1.03 and 0.88 to 0.98 , respectively. The change trend of the model curves is basically consistent with that of the test data. By comparing the two model curves, the curve is divided into three stages. With the increase of shear displacement, the first stage is characterized by shear stress of the hyperbolic model is larger than that of the Gompertz- $\mathrm{C}$ model, the second stage is characterized by shear stress of the Gompertz- $\mathrm{C}$ model becoming more larger, and the last stage becomes the same as the first stage. The three stages of the two models are illustrated in Figure 12. From the above analysis, it can be concluded that the hyperbolic model is more suitable for shear stress hardening in the last stage, and the Gompertz-C model is more suitable for shear stress stable or softening in the last stage. By comparing with the hyperbolic model, the Gompertz-C model can be used to study the shear stressshear displacement relationship of sand-steel interface.

3.3. Shear Strength Index. The shear strength failure formula of Mohr-Coulomb is applied to the linear fitting of the relationship between peak shear stress and the normal stress, and the shear strength index of the interface is obtained, as shown in Figure 13 and Table 6. Relationships between interface friction angle and groove width for steel-sand interface are shown in Figure 14. Increasing extent of interface friction angle with groove width is shown in Table 7. 

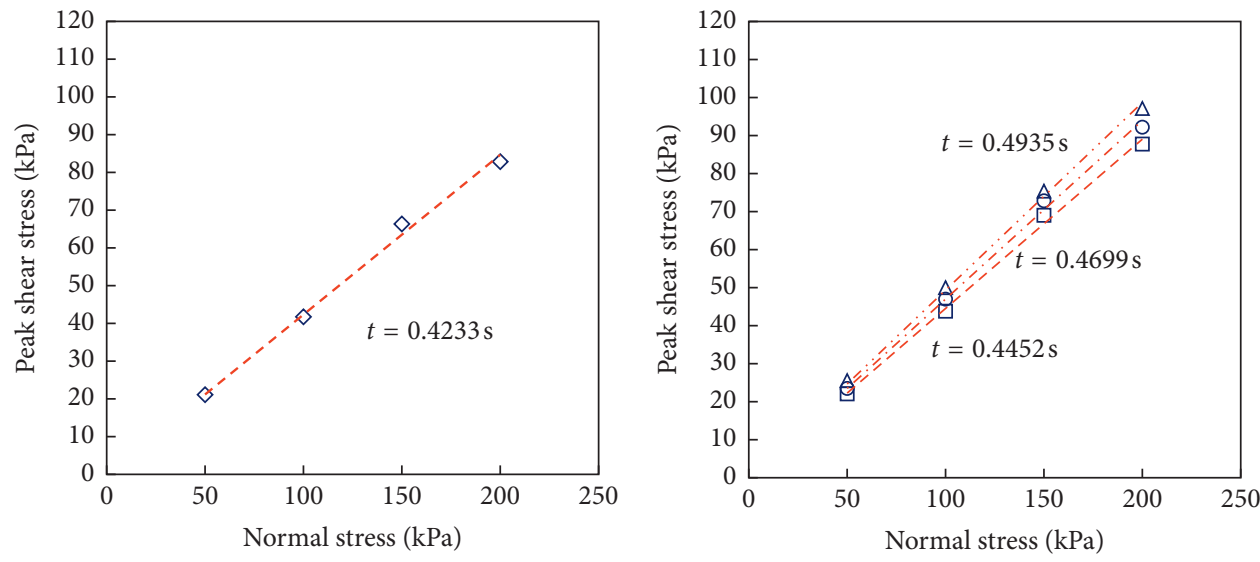

$\diamond$ Int-A

$\square$ Int-B-0

○ Int-B- $45^{\circ}$

$\Delta$ Int-B- $90^{\circ}$

(a)

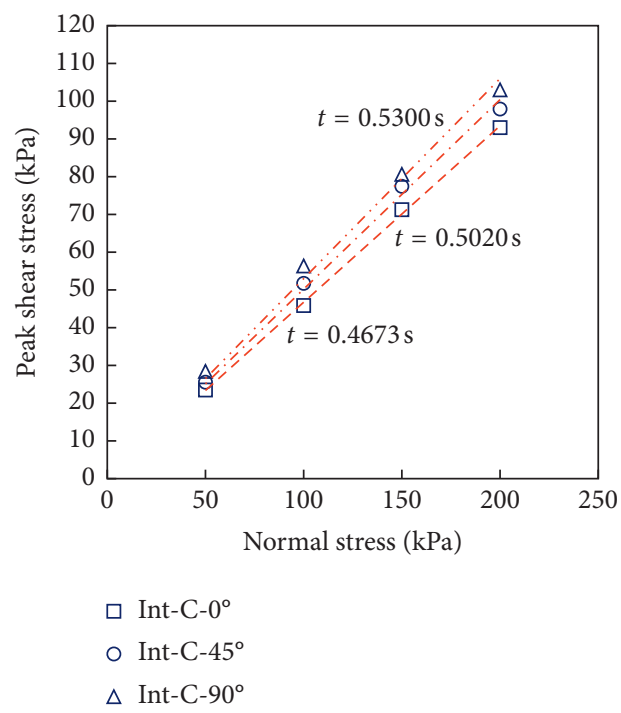

(c) (b)

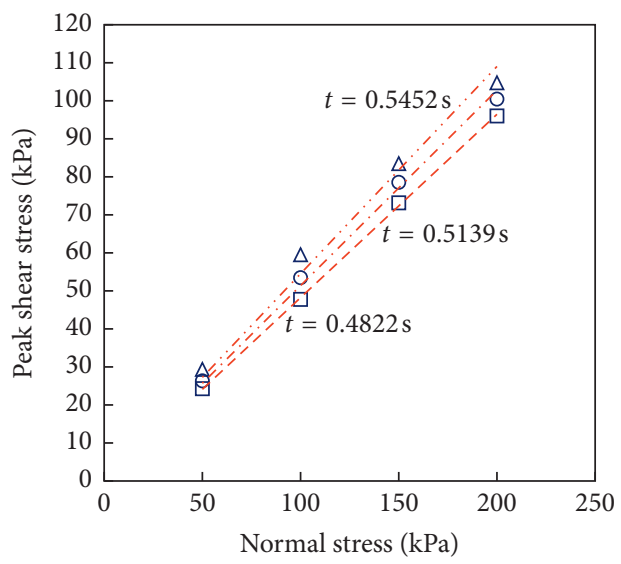

$\square$ Int-D-0
$\circ$ Int-D-45
$\Delta$ Int-D-90

(d)

Figure 13: Relationship between normal stress and peak shear strength for steel-sand interfaces. (a) Int-A. (b) Int-B. (c) Int-C. (d) Int-D.

TABLE 6: Interface friction angle and fitting formula.

\begin{tabular}{lccc}
\hline Interface & Interface friction angle $\left(^{\circ}\right)$ & Fitting formula & $R^{2}$ \\
\hline Int-A & 22.94 & $\tau=0.4233 \sigma$ & 0.995 \\
Int-B-0 $^{\circ}$ & 24.00 & $\tau=0.4452 \sigma$ & 0.997 \\
Int-B-45 $^{\circ}$ & 25.17 & $\tau=0.4699 \sigma$ & 0.997 \\
Int-B-90 $^{\circ}$ & 26.27 & $\tau=0.4935 \sigma$ & 0.998 \\
Int-C-0 $^{\circ}$ & 25.05 & $\tau=0.4673 \sigma$ & 0.999 \\
Int-C-45 $^{\circ}$ & 26.66 & $\tau=0.5020 \sigma$ & 0.996 \\
Int-C-90 $^{\circ}$ & 27.92 & $\tau=0.5300 \sigma$ & 0.992 \\
Int-D-0 $^{\circ}$ & 25.74 & $\tau=0.4822 \sigma$ & 0.999 \\
Int-D-45 $^{\circ}$ & 27.20 & $\tau=0.5139 \sigma$ & 0.996 \\
Int-D-90 $^{\circ}$ & 28.60 & $\tau=0.5452 \sigma$ & 0.984 \\
\hline
\end{tabular}

The results include the following: the fitting coefficient $R^{2}$ is above 0.98 , which shows a good fitting effect. The interface friction angle at the sand-steel interface ranges from $22^{\circ}$ to $29^{\circ}$, and the friction angle of the rough interface is larger than that of the smooth interface. It shows that the different surface morphology determines the different interface 


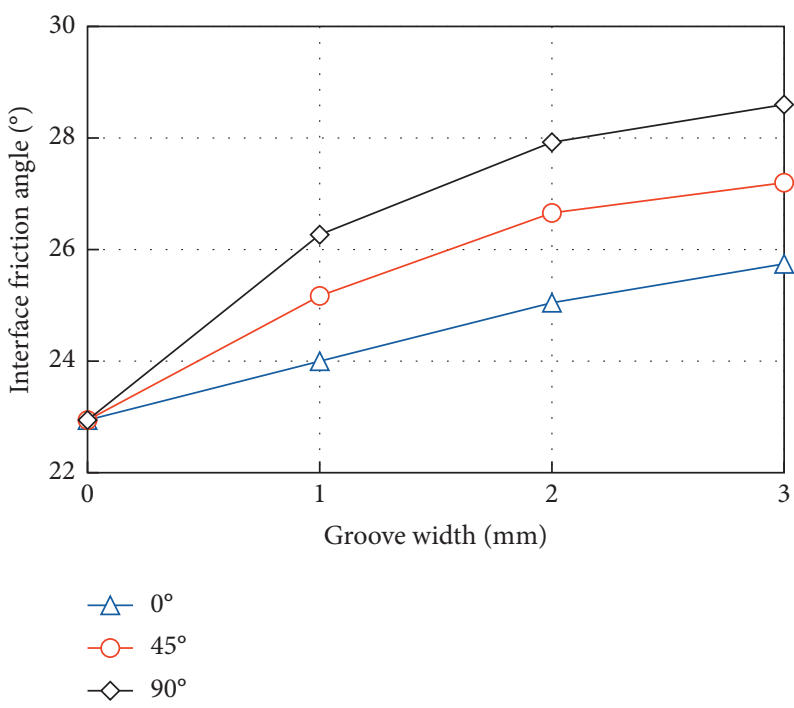

FIGURE 14: Relationship between interface friction angle and groove width for steel-sand interfaces.

TABLE 7: Increasing extent of interface friction angle with groove width.

\begin{tabular}{|c|c|c|c|c|c|c|c|}
\hline \multirow{2}{*}{ Groove angel $\left({ }^{\circ}\right)$} & \multicolumn{4}{|c|}{ Groove width $(\mathrm{mm})$} & \multirow{2}{*}{$F(\%)$} & \multirow{2}{*}{$G(\%)$} & \multirow{2}{*}{$H(\%)$} \\
\hline & 0 & 1 & 2 & 3 & & & \\
\hline 0 & 22.94 & 24.00 & 25.05 & 25.74 & 4.6 & 4.4 & 2.8 \\
\hline 45 & 22.94 & 25.17 & 26.66 & 27.20 & 9.7 & 5.9 & 2.0 \\
\hline 90 & 22.94 & 26.27 & 27.92 & 28.60 & 14.5 & 6.3 & 2.4 \\
\hline
\end{tabular}

strength index. Under the same groove shape and size, the interface friction angle increases with the intersection angle between the groove direction and the shear direction, the largest at $90^{\circ}$, the second at $45^{\circ}$, and the smallest at $0^{\circ}$. Because there is no groove at the smooth interface, the interface friction angle is the same at any rotation angle. Under the same groove angle, the interface friction angle increases with the groove width. As shown in Table 7, F, G, and $H$ represent the increasing extent of interface friction angle from $0 \mathrm{~mm}$ to $1 \mathrm{~mm}, 1 \mathrm{~mm}$ to $2 \mathrm{~mm}$, and $2 \mathrm{~mm}$ to $3 \mathrm{~mm}$. The corresponding value of $F, G$, and $H$ ranges from $4 \%$ to $15 \%, 4 \%$ to $7 \%$, and $2 \%$ to $3 \%$, respectively. The increasing extent of interface friction angle decreases with groove width, and this change rule is more obvious at the groove angle of $45^{\circ}$ and $90^{\circ}$ than at $0^{\circ}$.

\section{Conclusions}

In this paper, the shear behaviors of standard sand with steel plates are studied using an improved direct shear apparatus. The conclusions are as follows:

(1) The peak shear stress increases with normal stress and the angle between groove direction and shear direction. When the angle increases by $45^{\circ}$, the peak shear stress increases range from $4 \%$ to $13 \%$. The peak value of shear stress increases with groove width, for every $1 \mathrm{~mm}$ increase in groove width, and the increasing extent of peak shear stress ranges from $4 \%$ to $22 \%, 3 \%$ to $13 \%$, and $1 \%$ to $6 \%$, respectively. When the groove angle is $45^{\circ}$ and $90^{\circ}$, the increasing extent of peak shear stress decreases with the groove width, but when the groove angle is $0^{\circ}$, the decrease regularity of peak shear stress increasing extent is not obvious.

(2) The hyperbolic model and Gompertz- $\mathrm{C}$ model are used to study the shear stress-shear displacement curves of sand-steel interface. The ratio of the interface peak shear stress of the hyperbolic model to that of the Gompertz-C model ranges from 1.02 to 1.04. The ratio of the interface peak shear stress of the hyperbolic model and Gompertz-C model to that of the shear test ranges from 0.90 to 1.03 and 0.88 to 0.98 , respectively. The model curves are divided into three stages.

(3) The interface friction angle at the sand-steel interface ranges from $22^{\circ}$ to $29^{\circ}$, and the friction angle of rough interface is larger than that of the smooth interface. The interface friction angle increases with the intersection angle between the groove direction and the shear direction, the largest at $90^{\circ}$, the second at $45^{\circ}$, and the smallest at $0^{\circ}$. Under the same groove angle, the interface friction angle increases with groove width, for every $1 \mathrm{~mm}$ increase in groove width, and the increasing extent of interface friction angle ranges from $4 \%$ to $15 \%, 4 \%$ to $7 \%$, and $2 \%$ to $3 \%$, respectively. The increasing extent of interface 
friction angle decreases with groove width, and this change rule is more obvious at the groove angle of $45^{\circ}$ and $90^{\circ}$ than at $0^{\circ}$.

\section{Data Availability}

The data of the research conclusions in this paper are included within the article.

\section{Conflicts of Interest}

The authors declare that there are no conflicts of interest for this paper.

\section{Acknowledgments}

This work was funded by the National Natural Science Foundation of China (no. 51879246), the Natural Foundation of Shandong Province (no. ZR2019MEE056), the Science and Technology Project of Tibet Autonomous Region (no. XZ202001ZY0013G), the Science and Technology Development Plan Project of Weifang City (no. 2019GX087), and the Transportation Technology Project of Shandong Province (no. 2020B23).

\section{References}

[1] H. L. Kou, J. Chu, W. Guo, and M. Y. Zhang, "Field study of residual forces developed in PHC pipe piles," Canadian Geotechnical Journal, vol. 53, no. 4, 2015.

[2] H. L. Kou, W. Guo, and M. Y. Zhang, "Pullout performance of GFRP anti-floating anchor in weathered soil," Tunnelling \& Underground Space Technology, vol. 49, pp. 408-416, 2015.

[3] J. He, Y. F. Gao, Z. X. Gu, J. Chu, and L. Y. Wang, "Characterization of crude bacterial urease for $\mathrm{CaCO}_{3}$ precipitation and cementation of silty sand," Journal of Materials in Civil Engineering, vol. 32, no. 5, Article ID 04020071, 2020.

[4] X. Y. Ye, S. Y. Wang, S. Zhang, X. Xiao, and F. Xu, "The compaction effect on the performance of a compactiongrouted soil nail in sand," Acta Geotechnica, vol. 15, no. 10, pp. 2983-2995, 2020.

[5] X. Y. Ye, S. Y. Wang, Q. Li, S. Zhang, and D. C. Sheng, "Negative effect of installation on performance of a compaction-grouted soil nail in poorly graded stockton beach sand," Journal of Geotechnical and Geoenvironmental Engineering, vol. 146, no. 8, Article ID 04020061, 2020.

[6] J. G. Potyondy, "Skin friction between various soils and construction materials," Géotechnique, vol. 11, no. 4, pp. 339-353, 1961.

[7] M. Uesugi and H. Kishida, "Influential factors of friction between steel and dry sands," Soils and Foundations, vol. 26, no. 2, pp. 33-46, 1986.

[8] M. Uesugi, H. Kishida, and Y. Tsubakihara, "Behavior of sand particles in sand-steel friction," Soils and Foundations, vol. 28, no. 1, pp. 107-118, 1988.

[9] E. Evgin and K. Fakharian, "Effect of stress paths on the behaviour of sand-steel interfaces," Canadian Geotechnical Journal, vol. 33, no. 33, pp. 853-865, 1996.

[10] K. Fakharian and E. Evgin, "Cyclic simple-shear behavior of sand-steel interfaces under constant normal stiffness condition," Journal of Geotechnical and Geoenvironmental Engineering, vol. 123, no. 12, pp. 1096-1105, 1997.
[11] V. D. Gennaro and R. Frank, "Elasto-plastic analysis of the interface behaviour between granular media and structure," Computers and Geotechnics, vol. 29, no. 7, pp. 547-572, 2002.

[12] M. Boulon, V. N. Ghionna, and G. Mortara, "A strainhardening elastoplastic model for sand-structure interface under monotonic and cyclic loading," Mathematical and Computer Modelling, vol. 37, no. 5-6, pp. 623-630, 2003.

[13] C. S. Desai, S. K. Pradhan, and D. Cohen, "Cyclic testing and constitutive modeling of saturated sand-concrete interfaces using the disturbed state concept," International Journal of Geomechanics, vol. 5, no. 4, pp. 286-294, 2005.

[14] G. Mortara, A. Mangiola, and V. N. Ghionna, "Cyclic shear stress degradation and post-cyclic behaviour from sand-steel interface direct shear tests," Canadian Geotechnical Journal, vol. 44, no. 7, pp. 739-752, 2007.

[15] G. Mortara, D. Ferrara, and G. Fotia, "Simple model for the cyclic behavior of smooth sand-steel interfaces," Journal of Geotechnical and Geoenvironmental Engineering, vol. 136, no. 7, pp. 1004-1009, 2010.

[16] J. Zhou, J. F. Chen, J. F. Xue, and J. Q. Wang, "Micromechanism of the interaction between sand and geogrid transverse ribs," Geosynthetics International, vol. 19, no. 6, pp. 426-437, 2012.

[17] C. M. Martin, S. A. Jefferis, and C. Lam, "Effects of polymer and bentonite support fluids on concrete-sand interface shear strength," Géotechnique, vol. 64, no. 1, pp. 28-39, 2014.

[18] F. Y. Liu, P. Wang, X. Geng, J. Wang, and X. Lin, "Cyclic and post-cyclic behaviour from sand-geogrid interface large-scale direct shear tests," Geosynthetics International, vol. 23, no. 2, pp. 1-11, 2016.

[19] P. Vangla and M. Latha Gali, "Effect of particle size of sand and surface asperities of reinforcement on their interface shear behaviour," Geotextiles and Geomembranes, vol. 44, no. 3, pp. 254-268, 2016.

[20] B. Farhadi and A. Lashkari, "Influence of soil inherent anisotropy on behavior of crushed sand-steel interfaces," Soils and Foundations, vol. 57, no. 1, pp. 111-125, 2017.

[21] S. J. Feng, X. Liu, H. X. Chen, and T. Zhao, "Micro-mechanical analysis of geomembrane-sand interactions using DEM," Computers \& Geotechnics, vol. 94, pp. 58-71, 2018.

[22] M. Khemissa, N. Tallah, and B. Bencheikh, "Experimental and numerical modeling of the sand-steel interface behavior under monotonic loading," Innovative Infrastructure Solutions, vol. 3, no. 1, p. 25, 2018.

[23] A. Martinez, S. Palumbo, and B. D. Todd, "Bioinspiration for anisotropic load transfer at soil-structure interfaces," Journal of Geotechnical and Geoenvironmental Engineering, vol. 145, no. 10, Article ID 04019074, 2019.

[24] X. Wang, X. Z. Wang, C. Q. Zhu, and Q. S. Meng, "Shear tests of interfaces between calcareous sand and steel," Marine Georesources \& Geotechnology, vol. 37, no. 5, pp. 1-10, 2018.

[25] G. W. Clough and J. M. Duncan, "Finite element analyses of retaining wall behavior," Journal of Soil Mechanics and Foundation Division, vol. 97, no. 12, pp. 1657-1673, 1971.

[26] Z. Z. Yin, H. Zhu, and G. H. Xu, "Numerical simulation of the deformation in the interface between soil and structural material," Chinese Journal of Geotechnical Engineering, vol. 16, no. 3, pp. 14-22, 1994.

[27] L. M. Hu and J. L. Pu, "Damage model of soil-structure interface," Rock and Soil Mechanics, vol. 23, no. 1, pp. 6-11, 2002.

[28] A. Z. Zhou, T. H. Lu, and P. M. Jiang, "General description of soil-structure interface constitutive model based on generalized potential theory," Rock and Soil Mechanics, vol. 33, no. 10, pp. 1532-1536, 2012. 